\title{
Tele-Schooling as Distance Learning Approach in Schools of Pakistan During Pandemic COVID-19
}

\author{
Dr. Saghir Ahmad Ch. \\ Department of Education, Hazara University Mansehra \\ saghir.edu786@)gmail.com \\ Dr. Ayesha Batool \\ Assistant Professor \\ Lahore College for Women University \\ Dr. Muhammad Ajmal \\ Associate Professor \\ Department of Distance and Non Formal Education, AIOU
}

\begin{abstract}
Tele-schooling is a distance learning approach that is fruitful in COVID-19. The corona virus destroyed the world system desperately. All fields business, trade, educational institution etc. are closed due to pandemic virus and only one slogan in the world is "SOCIAL Distancing". The Ministry of Education introduced the tele-schooling as distance learning approach for school students in Pakistan during COVID-19. The purpose of launching new approach of teaching and learning is the continuity of students learning. The intention of researchers behind this study was to explore perceptions of students about tele-schooling at that time when corona damaged the world badly. This study was designed under survey design and correlational approach. It was descriptive study directed for collecting data from school students regarding teleschooling during uncertain atmosphere. One hundred and forty students were selected by convieninet sampling technique.A self-developed questionnaire regarding teleschooling in COVID-19 on five point likert scale was used for this study. The collected data were analyzed by applying descriptive and inferential statistical techniques. It is concluded that tele-schooling is helpful in distance learning during COVID-19. This approach is better source of developing skills and learning in pandemic situation. They found tele-schooling effective learning approach to accomplish the learning objectives. A strong association was there which indicated that all dimensions were essential and fruitful to measure the tele-schooling learning approach in COVID-19. The school students are happy and enjoying tele-schooling. Therefore, its presence should be there after pandemic COVID-19.
\end{abstract}

Key words: Tele-schooling, students, distance-learning approach, COVID-19.

\section{Introduction}

Education assumes a vital job in molding the eventual fate of a nation. It ensures future residents capability adds to sustainable growth and advances human safety (Shaw, Takeuchi, Gwee, \& Shiwaku, 2011). A pleasant and safe instructive condition contributes significantly to the physical and mental prosperity of kids and gives an establishment to them to become dynamic operators inside society. If instructive congruity is hindered because of characteristic dangers, 
students can without much of a stretch drop out of the instructive framework and are bound to be uneducated when they leave school and consequently hurting the nation's financial possibilities and wellbeing. Governments have a duty to guarantee compulsory education and training for all including youngsters, where some people pay attention to more than others. It is observed that students spend a healthy amount of time and energy at school and this implies it merits inspecting the wellbeing of them despite potential catastrophes during this time. It is significant that schools advance a wellbeing society that shields kids from calamities (Shah et al., 2018).

Individuals have utilized different instruments to speak with one another's since the start or their reality. The devices have created and expanded in assortment in corresponding to the improvement of individuals. Broad communications and the instruments used to ease communications have increased essential significance as a result of the fast change and advances in innovation and social advancement. Teaching skills regardless of whether inside a regular instructive foundation or through separation learning, requires the utilization of exact directions to empower students to follow the procedure and rehash the expertise (Hampton, 2002). Thus, conventional system has limitations and in this manner video-oriented instructional system have been looked for (Donkor, 2010).

The utilization of video in the conveyance of practical lectures has a few preferences that are accepted. One such favorable position, progressed by Mishra (2001), is that video is helpful in demonstrating viable and genuine exercises. The video can be utilized to catch unsafe and exorbitant examinations for introduction and for rehashed use. For the educating skills and abilities to regular and distance students, Hampton (2002) considers video to be "a fruitful medium since it interfaces the sound and the visual together to give a multisensory experience to the student" ( $p$. 85). He said video makes it feasible for the student to play, replay, delay, and rewind to explicit segments of the lecture and further stated that "training and practice is so significant in creating competency, video is especially very much put” (p. 85). Zhang, Zhou, Briggs, and Nunamaker (2006) described that "video permits students to see genuine articles and actual scenes and to tune in to portrayal" (p. 17). Despite the fact that video assets are costly to create or develop. Tooth (2000) conceded that they are valuable where actual shows of abilities are required. From a monetary viewpoint, Jung (2005) said the value of utilizing video assets in the cost investment funds anticipated from reuse. 
Researchers like Zhang et al., (2006) have demonstrated that research proposes that educational video expands students' enthusiasm for the subject, just as inspiration to learn. Additionally, it has been observed that learners find video materials appealing and prompting fulfillment (Kearney \& Treagust, 2001; Piotrow, Khan, Lozare, \& Khan, 2000). Furthermore, Zhang et al. (2006) have detailed beneficial outcomes of intuitive video on both learning results and student fulfillment in e-learning. Donkor (2010) has analyzed the instructional viability of the video-based teaching and the customary teaching resources. He saw the video-oriented teaching as educationally better than the regular instructions resources for the instructing of reasonable abilities in distance environment. Students are furnished with self-instructional resources to learn at home all alone, and they go to instructional activities through tele schooling and online. The learning objectives are accomplished through conventional teaching materials; handy abilities obtaining is accomplished through either regular or video instructions that students get to utilizing technology.

Masrom (2007) depicted apparent handiness as how much the client accepts that utilizing the innovation will improve their work performance, while saw usability "alludes to how easy the person sees utilizing the innovation will be" (p. 3). As indicated by Masrom, both perceptions helpfulness and convenience are viewed as unmistakable components impacting the learners demeanor toward utilizing the innovation, however this usability is additionally estimated to impact seen value and mentality toward utilizing the innovation. Therefore, such behavior toward utilizing the technology decides the attitude expectation to utilize that innovation.

New coronavirus and the subsequent COVID-19 illness have more schools and regions confronted with the test of how to keep up progression of educating and learning while at the same time confronting the risk of expanded school terminations. The prompt enticement and apparently straightforward arrangement is to lead school remotely utilizing on the web and teleschooling assets to associate learners and instructors. Teleschooling approach has advantages for example, proceeding with the school year without broad interferences and multi-week school terminations. Anyway making a viable tele-learning arrangement is difficult. Moving educational systems to a teleschooling learning condition is not only a specialized issue. It is an educational and instructional test. Innovation is the methods for conveyance. An effective exertion to move school outside of conventional class and building structure requires a nearby cross-joint effort between instructional, substance, and innovation groups. It is an instructive change that requires quick 
mobilization over the country. Prior to pulling the trigger on an innovation activity to move guidance to a teleschooling, it is important to know the circumstances. Getting ready to move training outside of conventional physical class in light of COVID-19 entails thought, collobaration and situational decisions.

The government of Pakistan took special initiative for distance education and arranged and executed interchange models of instruction for students. Prime minister Imran Khan inaugurated the new teaching approach tele-schooling in Pakistan in mid-April 2020 during pandemic COVID19. He and Ministry of Education launched and introduced tele-schooling for students learning in pandemic situation. The purpose of tele-schooling is the continuity of learning activities in drastic environment. Tele-schooling video based teaching show pragmatic abilities, including in the conveyance of a square laying and cementing course by means of separation learning. It is the matter of development of society by providing learning resources and opportunities to students in corona situation.

\subsection{Significance of the Study}

In this time of quickly propelling innovation, broad communications and television have become urgent devices for learning. For school, the internet and television are an extraordinary source to help instruction (Sunal \& Haas, 2002). The instructive outcomes of trend setting innovation and the profileration of broad communications apparatuses will unavoidably influence educators and school learners. An instructor profiting by these devices proficiently in the training procedure will have increasingly productive and compelling classes; assist students with learning in a brief timeframe and add to students' lasting learning too.Understanding this is conceivable by deciding the impression of educators and instructor competitors of broad communications. Therefore, in this context there are just scarcely study the impression of instructors and educator competitors of the utilization of teleschooling for students. It is additionally importantstudy to exploring the impression of students about teleschooling and the utilization of this device for learning. It is supposed that by knowing the views of students about teleschooling for education may reveal insight into the present circumstance in COVID-19 and supplement to the current usage. The findings of the study may fruitful to know the importance and worth of teleschooling in education system of Pakistan. 


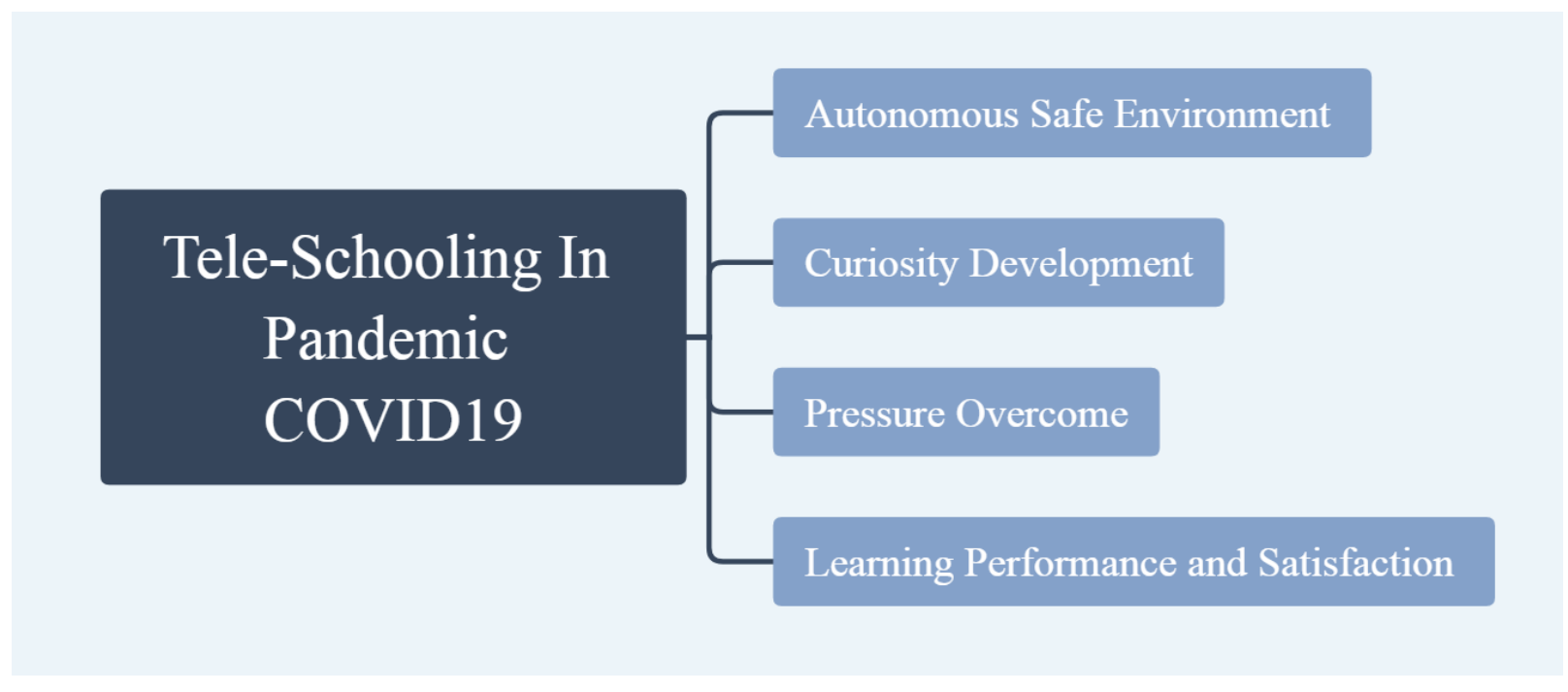

Figure 1:Conceptual framework of Tele-schooling and sub-dimensions

\subsection{Objectives of the Study}

This study was conducted to accomplish the following objectives:-

1. Identify the students' perceptions about tele-schooling as distance learning approach in schools during COVID-19.

2. Explore relationship among subfactors of tele-schooling as distance learning approach in schools.

3. Develop structural equation modeling of tele-schooling as distance learning approach in schools during COVID-19 through path analysis.

\section{Methodology}

\subsection{Research Design}

This study was designed under survey design and correlational approach. It was descriptive study directed for collecting data from students regarding teleschooling during uncertain atmosphere of COVID-19.

\subsection{Population and Sampling}

The population of the research was comprised of schools students of Punjab district who were enjoying learning from teleschooling. The convieninet sampling technique was used for selecting sampling. This sampling technique was used due to Corna Virus uncertain circumstances 
in country and all over the globe. Therefore, total number of sample was one hundred and forty students.

\subsection{Instrumentaion}

A self-developed questionnaire related to teleschooling in COVID-19 on five point likert scale was used for this study. The questionnaire contained four sub-factors (Autonomous Safe Environment, Curiosity Development, Pressure Overcome, and Learning Performance and Satisfaction) to meausre teleschooling as learning approach COVID-19.Each factor had five statements. The total items in questionnaire were twenty. The questionnaire was developed by keeping in mind the current situation of society. Pilot testing was determined to ensure validity and reliability of questionnaire. The content validity of questionnaire was ensured by experts' opinions. The reliability was checked by Cronbach Alpha. The value was .85, which is statistical significant.

\subsection{Data Collection and Analysis}

It was hard task to collect data in environment of COVID-19. Data were collected by different approaches. Schools' students were approached in different ways (social media, face to face) and took data. It were analyzed by applying descriptive and inferential statistical techniques. In descriptive, means and standard deviations were applied and pearson $r$ and structural equation modeling through path analysis were developed in inferential statistics. The detail data analysis is under following. 


\section{Results and Findings}

Table 1. Descriptive statistics of Tele-schooling Distance Learning Approach

\begin{tabular}{lcc}
\hline Stems & $M$ & $D$ \\
\hline Tele-schooling helps in distance learning during Covid19. & 3.89 & .875 \\
I learn independently by Tele-schooling & 3.83 & .798 \\
Tele schooling is a better source of learning and skills during Covid19. & 3.80 & .895 \\
I find the Tele schooling is effective in meeting the learning objectives. & 3.65 & 1.023 \\
It provides self-direction learning. & 3.83 & 1.109 \\
I feel curiosity by watching Tele schooling & 4.26 & .829 \\
Tele-schooling develops interest. & 4.23 & .672 \\
I find the Tele schooling is enjoyable. & 4.30 & .537 \\
Tele schooling should continue after COVID19. & 4.15 & .590 \\
Tele schooling videos make it easy to learn quickly. & 4.10 & .696 \\
I take no pressure in Tele schooling & 4.07 & .813 \\
I learn new things in Tele schooling without teacher pressure & 4.48 & .652 \\
I spend more time in study to learn things. & 4.21 & .766 \\
Tele-schooling is stress free. & 4.07 & .750 \\
Tele-schooling reduces the work burden. & 4.11 & .667 \\
Tele schooling increases my knowledge & 4.21 & .680 \\
I perform better in Tele schooling & 3.88 & .961 \\
Tele schooling brings concepts clarity. & 4.06 & .635 \\
I feel satisfaction by Tele schooling learning. & 4.13 & .681 \\
Tele schooling is highly interesting method in epidemic environment. & 4.15 & .611 \\
\hline
\end{tabular}

Table 1 shows the means and standard deviations values related to tele-schooling distance learning approach. Students were asked about tele-schooling and their interests in distance learning. They said tele-schooling is helpful in distance learning during COVID-19. They learnt independently in new learning approach. This approach is better source of developing skills and learning in pandemic situation. They found tele-schooling effective learning approach to accomplish the learning objectives. They sought self-direction learning at their homes. They felt curiosity and took interest in learning by tele schooling. They enjoyed this new teaching approach. 
They said it should continue after COVID-19. The lesson videos make it easy for students to learn rapidly. They had no pressure and anxiety in tele schooling education. It is stress free environment. They spent most of the times in tele schooling. It reduced the work burden of students and increased their level of knowledge. Tele schooling brought concepts clarity in students. They felt satisfaction in tele education. It is highly interesting approach in pandemic situation.

Table 2. Relationship between Tele-Schooling and its Sub-Factors

\begin{tabular}{lccccc}
\hline Factors & 1 & 2 & 3 & 4 & 5 \\
\hline Autonomous Safe Environment & 1 & $.348^{* *}$ & $.241^{*}$ & $.276^{*}$ & $.744^{* *}$ \\
Curiosity Development & & 1 & $.431^{* *}$ & $.339^{* *}$ & $.699^{* *}$ \\
Pressure Overcome & & & 1 & $.499^{* *}$ & $.706^{* *}$ \\
Learning Performance and Satisfaction & & & & 1 & $.701^{* *}$ \\
Tele-Schooling in COVID19 & & & & 1 \\
\hline
\end{tabular}

Table 2 depicts the relationship between tele-schooling and its sub-factors. A healthy and strong correlation was exit among variable and sub-dimensions. There was strong significant association of dimensions; autonomous safe environment $r=.744^{* *}$, curiosity development $r=$ $.699^{* *}$, pressure overcome $r=.706^{* *}$, and learning performance and satisfaction $r=.701^{* *}$ with new learning approach tele-schooling. It is concluded that strong association is there which indicates that all dimensions are essential and fruitful to measure the tele-schooling learning approach in COVID-19. 


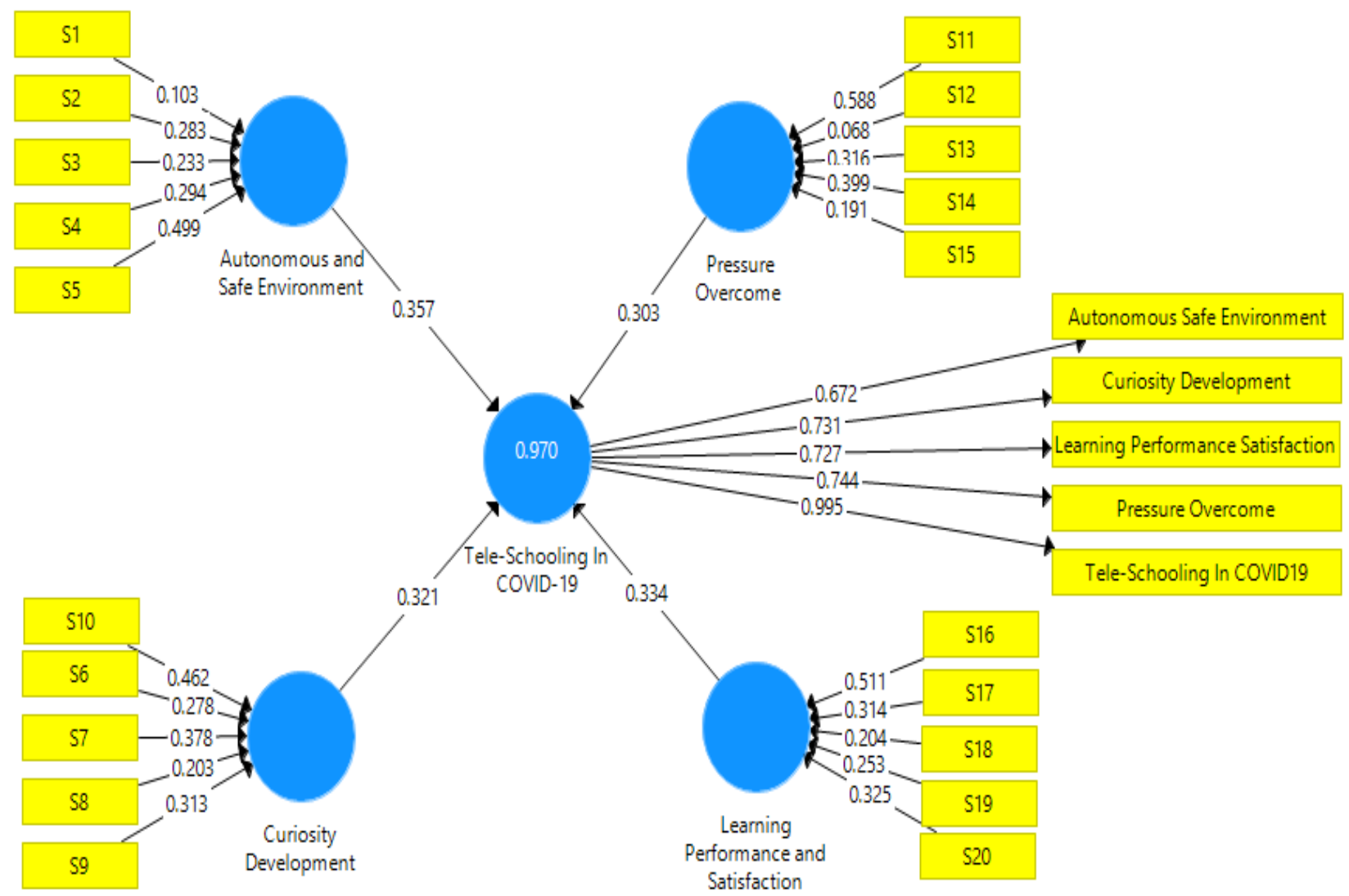

Figure 2: Structural equation modeling of Tele-schooling and sub-dimensions

Above figure is relatet to structural equation modeling of Tele-schooling and subdimensions. The variabe tele schooling consists of four dimensions. Tele schooling in COVID-19 is in middle and four sub factors around it in blue circles. Each factor is load with items in yellow color. The factors autonomous safe environment, curiosity development, learning performance and satisfaction, and pressure overcome have strong association with tele schooling. All dimensions are essential to meaure students satisfaction regarding tele schooling learning approach in COVID-19. 


\section{Path Coefficients}

\begin{tabular}{|c|c|c|}
\hline \multirow[t]{2}{*}{ Matrix } & 拱育 Path Coefficients & \multirow[b]{2}{*}{ Tele-Schooling In COVID-19 } \\
\hline & & \\
\hline \multicolumn{2}{|c|}{ Autonomous and Safe Environment } & 0.357 \\
\hline \multicolumn{2}{|c|}{ Curiosity Development } & 0.321 \\
\hline \multicolumn{2}{|c|}{ Learning Performance and Satisfaction } & 0.334 \\
\hline \multicolumn{2}{|c|}{ Pressure Overcome } & 0.303 \\
\hline
\end{tabular}

Figure 3: Path coefficients of Tele-schooling and sub-dimensions

Path coefficients figure shows the dimensions loadings of tele schooling with it. The factors autonomus and safe environment .357 , curiosity development .321, learning performance and satisfaction .334, and pressur overcome .303 have relationship with tele schooling. All factors showed the standard criterial in developing model.

\section{R Square}

\begin{tabular}{|c|c|c|c|c|c|}
\hline \multirow[t]{2}{*}{ 婳 } & \multirow[t]{2}{*}{ Matrix } & 掉音 R Square & 掉产 & R Square Adjusted & \multirow[b]{2}{*}{ R Square Adjusted } \\
\hline & & & & R Square & \\
\hline \multicolumn{4}{|c|}{ Tele-Schooling In COVID-19 } & 0.970 & 0.969 \\
\hline
\end{tabular}

Figure 4: $\mathrm{r}$ square of Tele-schooling

Figure shows the values of $r$ square and $r$ square adjusted of tele schooling in COVID-19. Researchers Ahmad, Batool, and Hussain (2019) described that $r$ square value is acceptable at 3 . However, $r$ square value of tele schooling in COVID-19 is .97, which is above than desired standard point and higly accepted. 
International Journal of Distance Education and E- Learning (IJDEEL) Volume VI- Issue I (December 2020)

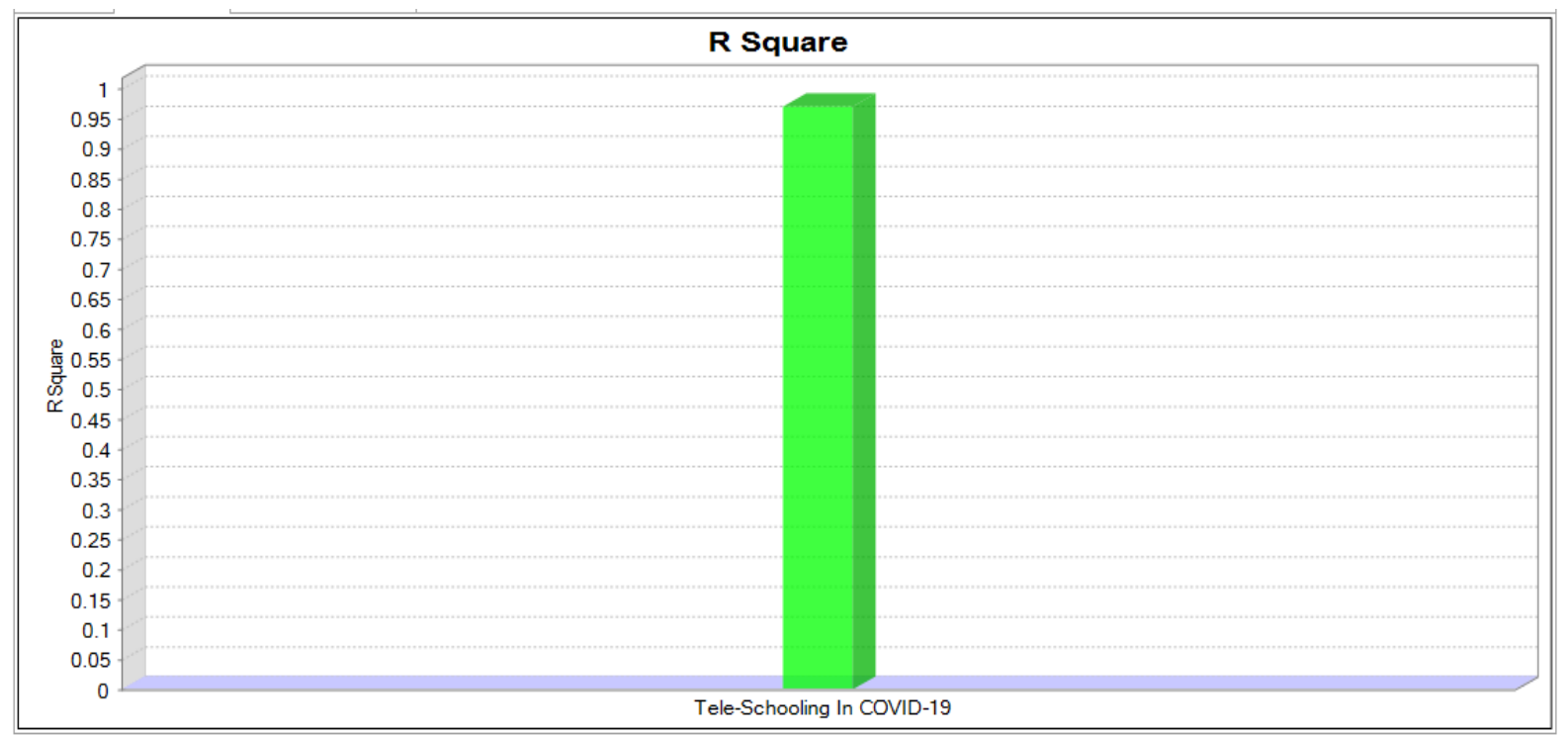

Figure 5: r square of Tele-schooling

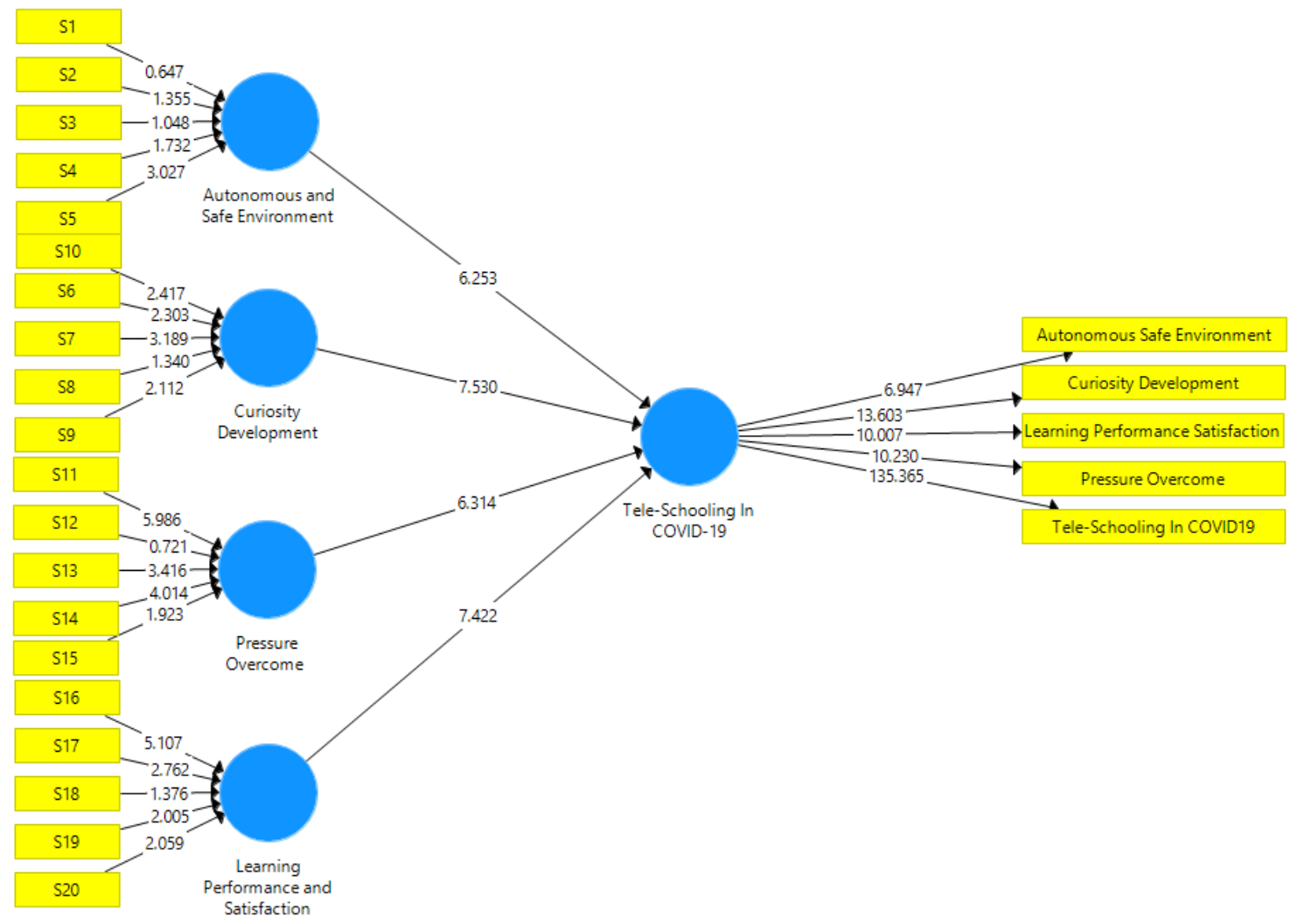

Figure 6: Bootstrapping structural equation modeling of Tele-schooling and sub-dimensions 
Above figure is relatet to bootstrapping structural equation modeling of Tele-schooling and sub-dimensions. The variabe tele schooling consists of four dimensions arranged left side of main variable. Tele schooling in COVID-19 is in middle and four sub factors around it in blue circles. For bootstrapping each factor is load with items in yellow color. The factors autonomous safe environment, curiosity development, learning performance and satisfaction, and pressure overcome have strong association with tele schooling. All dimensions are essential to meaure students satisfaction regarding tele schooling learning approach in COVID-19.

\section{Path Coefficients}

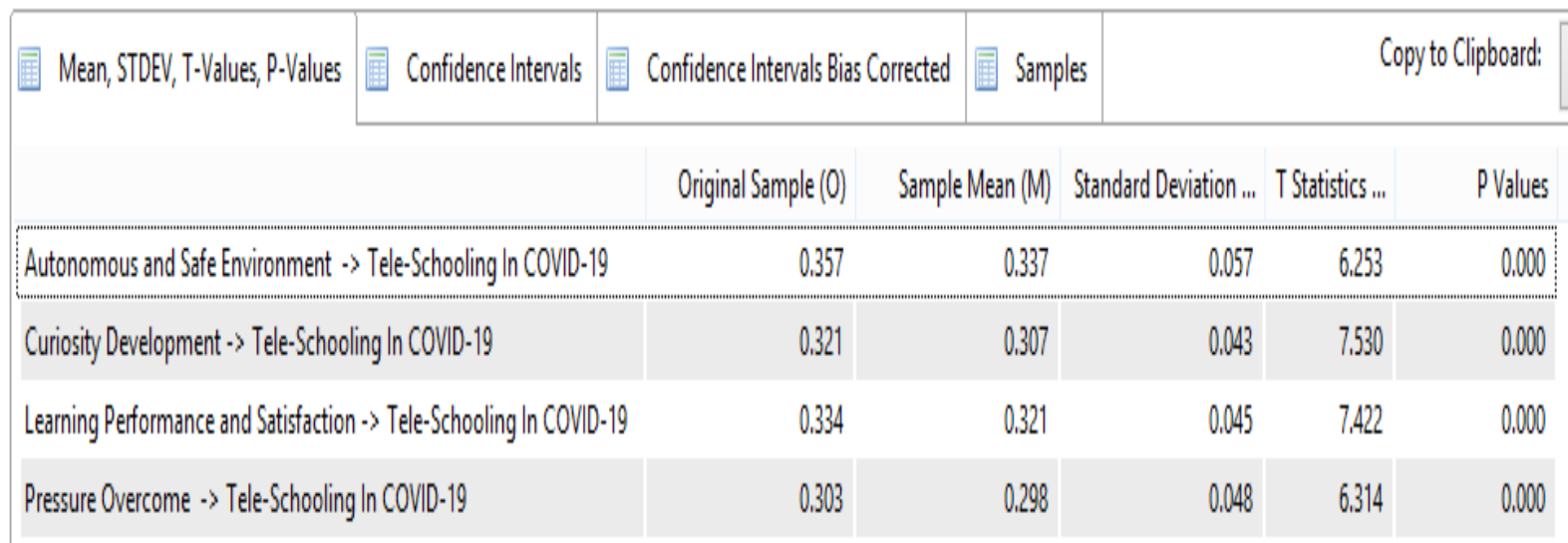

Figure 7: Bootstrapping path coefficients of Tele-schooling and sub-dimensions

This figure contains the bootstrapping path coefficients of Tele-schooling and subdimensions. It shows the means, standard deviations, t-statistics, and p-values. Researchers Ahmad and Hussain (2019) and Hair (2014) stated that t value should above 1.96, and p value must below than .05 in structural modelling. However, the values of tele schooling's dimensions are autonomous safe environment $T=6.253, P=.001$, curiosity development $T=7.530, P=.001$, learning performance and satisfaction $T=7.422, P=.001$, and pressure overcome $T=6.314, P=$ .001. All dimensions shows positive, strong and significant values, which are above than standard point. There is goodnes of fit in this model. It seems that tele schooling and its dimensions are interrelated that is beauty of model. 


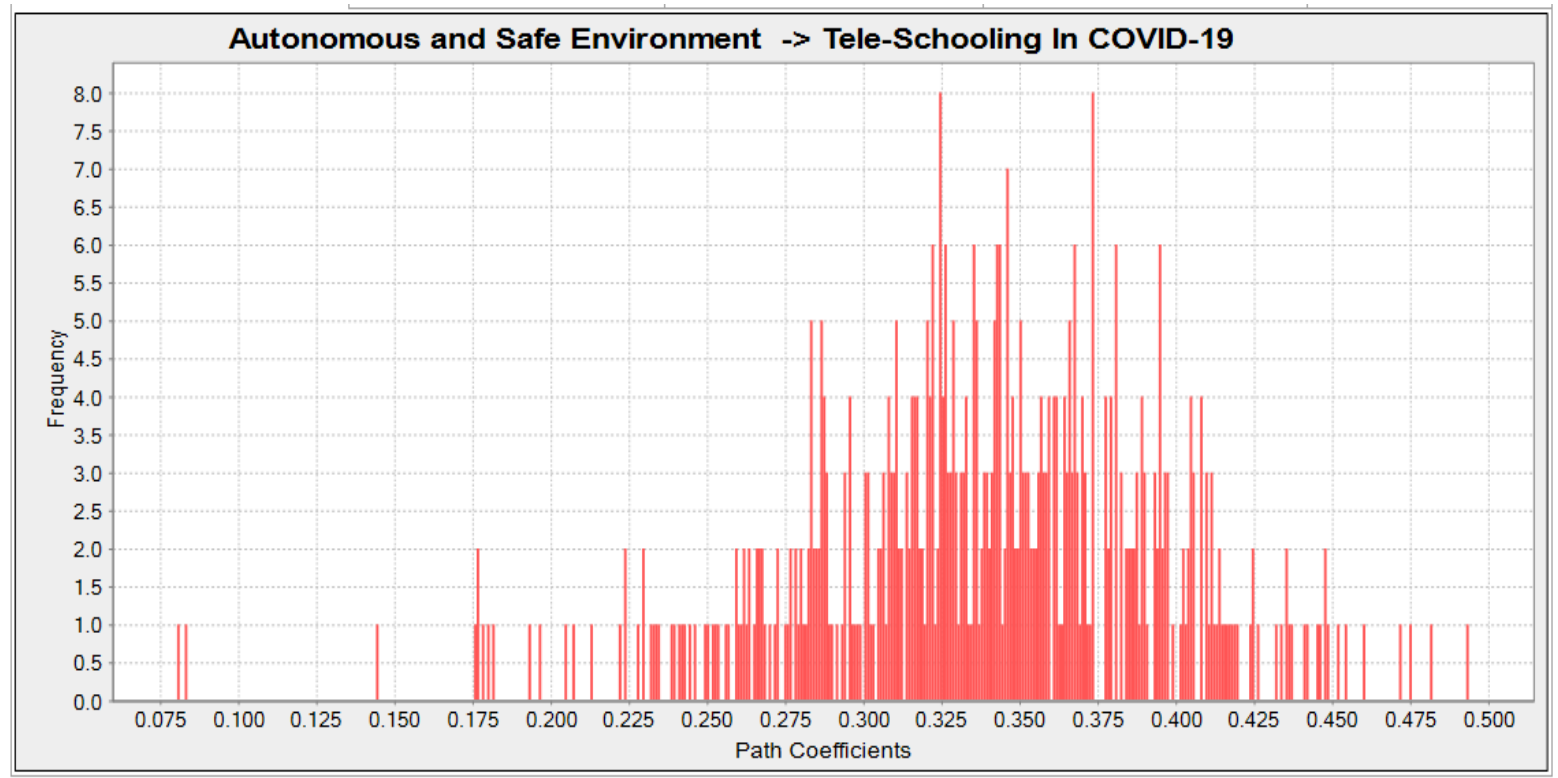

Figure 8:Path coefficients histogram of autonomous environment and Tele-schooling COVID19

Figure 8 shows the histogram of tele schooling. Ahmad and Hussain (2019) described in study that as indicated James (2009) histograms for path analysis developed by appropriatecluster model to participants which repliedTele-schooling new learning approach in COVID-19. The red lines specify path coefficient values of respondents againist variables. There are $\mathrm{x}$-axis and $\mathrm{y}$-axis in model. The $\mathrm{X}$ - axis is way coefficient esteem (barring values with supreme extent surpassing 1), and y- axis is number of participants with coefficients of this value. It is observed that model of fit exists in data of students regarding tele-schooling COVID-19.

\section{Discussion}

Researchers introduced the tele-schooling a new distance learning approach in Pakistan during Pandemic COVID-19. The intention of researchers behind this study was to explore perceptions of students about tele-schooling at that time when corona damaged the world badly. In such situation where all worry due to corona virus where it also affected education system severely in all over the world. It was observed in findings of study that students said tele-schooling is helpful in distance learning during COVID19. They learnt independently in new learning approach. This approach is better source of developing skills and learning in pandemic situation. They found tele-schooling effective learning approach to accomplish the learning objectives. 
These results are aligned with findings of previous study which conducted in other settings. A study was led by Nicolau, Henter, Roman, Neculau, and Miclaus (2020) in Romania on TeleEducation under the COVID-19 crisis.

Donkor (2010) directed a study in Ghana related to video based teaching and learning. He demonstrated in findings high acknowledgment and fulfillment of the separation students with the utilization of the video-based teaching where students can learn and develop their skilss and abilities. The students communicated high apparent convenience, usability, and expectation to utilize the video oriented instructions in learning viable aptitudes. The students additionally explored the applicable resources, effective, pleasant, and fascinating, and would prescribe them to their classmates for use. The communicated high acknowledgment of and fulfillment with the video teaching learning resources was, to a huge degree, and uniformity among the participants of the research. Therefore, regardless of setting, the students for the most part seemed positive about their encounters in the utilization of the video for distance learning to learn things and enhance abilities.

\section{Conclusions}

This study was conducted to to keep in mind the current situation of world especially Pakistan. The education system affected badly due to corona virus. The world has been locked down and human biengs are in their homes due to corona. Peoples have been banned to come out from homes and arranged public gatherings. There is only one slogan at that time and that is Social Distancing. The safety of humans is in social distancing just. The education system in Pakistan also closed in pandemic situation. The education system is going towards online teaching and learning in Pakistan. Similarly, after realizing the current situation the ministry of education introduced the tele-schooling as distance learning approach for school students in Pakistan. The Prime Minister of Pakistan Imran Khan launched tele-schooling in april 2020. The purpose of launching new approach of teaching and learning is the continuity of students learning. Nobody knows that when would be COVID-19 controlled and daily lives come back into routine. There is no vaccination of corona virus still but medical staff of countries is busy in preparation. Therfore, it would take time and after vaccination the after shocks of COVID-19 would there. 
Tele-schooling is new distance learning approach in schools which is getting popularity in the worldwide due to Pandemic COVID-19. This study was conducted to identify the students' perceptions about tele-schooling as distance learning approach in schools during COVID-19. The relationship was explored among subfactors of tele-schooling as distance learning approach in schools and developd structural equation modeling of tele-schooling as distance learning approach in schools during COVID-19 through path analysis. This survey study may fruitful to know the importance and worth of teleschooling in learning of school' students.A self-developed questionnaire related to teleschooling in COVID-19 contained four sub-factors (Autonomous Safe Environment, Curiosity Development, Pressure Overcome, and Learning Performance and Satisfaction) was used to meausre teleschooling as learning approach in corona virus. The questionnaire was developed by keeping in mind the current situation of society. Students were asked about tele-schooling and their developing interests in distance learning. It is concluded that tele-schooling is helpful in distance learning during Pandemic19. Students learnt independently in new learning approach. This approach is better source of developing skills and learning in pandemic situation. They found tele-schooling effective learning approach to accomplish the learning objectives. They sought self-direction learning at their homes. They felt curiosity and took interest in learning by tele schooling. They said it should continue after COVID-19. They had no pressure and anxiety in tele schooling education. It is stress free environment. They spent most of the times in tele schooling. It reduced the work burden of students and increased their level of knowledge. Tele schooling brought concepts clarity in students. They felt satisfaction in tele education. It is highly interesting approach in pandemic situation. It is concluded that strong association is there which indicates that all dimensions are essential and fruitful to measure the tele-schooling learning approach in COVID-19. It is concluded that tele schooling is new learning approach and students are busy to enjoy and learn things due to tele-education. This technique has acquired admiration and acceptance at large extent in very short time. According to school students, tele-schooling should be there after pandemic situation. Therefore, tele-schooling is effective and interesting learning approach that may develop students' interest and enhance their motivation level.

\subsection{Recommendations}

Followings are some recommendations which are representing the findings of the study. 
1. Tele-education is common in advanced countries of the world but it is new learning concept in Pakistan and it should continue.

2. Students are happy and enjoying tele-schooling. Therefore, it should not stop. Its presence should be there after pandemic COVID-19.

3. There should be a study to explore teachers perceptions regarding importance of teleschooling and what they think about their future security in teaching after tele-education.

4. There should be more concepts clarity and it is possible relevant pictorial material in teleschooling.

5. There is a need to do work on developing practical skills through tele schooling. Practical exercises should be there at the end of each lesson.

6. There should be use daily life examples in tele schooling for more understanding and developing long term memory of stduents.

7. There is also need to conduct study on this topic of tele-schooling on big data. It may fruitful to understand more clear and visible situation and results of teleschooling by getting opinions of students regarding this.

\section{References}

Ahmad, S., \& Hussain, A. (2019). Authentication of psychosomatic capability and workplace life of teachers scales by structural equation modeling. Journal of Educational Research, 22(2), 68-81.

Ahmad, S., Batool, A., \& Hussain, A. (2019). Path relationship of time management and academic achievement of students in distance learning institutions. Pakistan Journal of Distance and Online Learning, 5(2), 191-208.

Donkor, F. (2010). Assessment of learner acceptance and satisfaction with video-based instructional materials for teaching practical skills at a distance. The International Review of Research in Open and Distributed Learning, 12(5), 74-92.

Hair, J. G. (2014). A primer on partial least squares structural equation modeling (PLS-SEM). Edinburgh Gate Harlow: Pearson Education Limited.

Hampton, C. (2002). Teaching practical skills. In A. K. Mishra \& J. Bartram (Eds.), Perspectives on distance education: Skills development through distance education (pp. 83-91). Vancouver, Canada: Commonwealth of Learning. Retrieved from http://www.col.org/SiteCollectionDocuments/Skills_Chapter09.pdf

Jung, I. (2005). Innovative and good practices of open and distance learning in Asia and the Pacific (A study commissioned by UNESCO, Bangkok). Retrieved from http:// unesdoc.unesco.org/images/0015/001529/152961e.pdf 
Kearney, M., \&Treagust, D. F. (2001). Constructivism as a referent in the design and development of a computer program using interactive digital video to enhance learning in physics. Australian Journal of Educational Technology, 17(1), 64-79.

Masrom, M. (2007). Technology acceptance model and e-learning. 12th International Conference on Education, Sultan Hassanal Bolkiah Institute of Education, Universiti Brunei Darussalam. Retrieved from http://eprints.utm.my/5482/1/ MaslinMasrom2006_Techn.pdf

Mishra, S. (2001). Designing online learning. Vancouver, Canada: Commonwealth of Learning. Retrieved from http://www.col.org/SiteCollectionDocuments/KS2001- 02_online.pdf

Nicolau, C., Henter, R., Roman, N., Neculau, A., \&Miclaus, R. (2020). Tele-Education under the COVID-19 crisis: Asymmetries in Romanian Education. Symmetry, 12(9), 1502.doi:10.3390/sym12091502

Piotrow, P., Khan, O., Lozare, B., \& Khan, S. (2000). Health communication programs: A distance education class within the John Hopkins University School of Public Health Distance Education Program. In M. Khosrowpour (Ed.), Web-based learning and teaching technologies: Opportunities and challenges. Hershey, PA: Idea Group Publishing.

Shah, A. A., Ye, J., Pan, L., Ullah, R., Shah, S. I. A., Fahad, S., \& Naz, S. (2018). Schools' flood emergency preparedness in Khyber Pakhtunkhwa Province, Pakistan. International Journal of Disaster Risk Science, 9(2), 181-194. Retrieved from https://doi.org/10.1007/s13753-018-0175-8

Shaw, R., Takeuchi, Y., Gwee, Q. R., \& Shiwaku, K. (2011). Disaster education: An introduction. Disaster Education, 7, 1-22. doi:10.1108/S2040-7262(2011) 0000007007

Sunal, C. S., \& Haas, M. E. (2002). Social studies for the elementary and middle grades. Boston: Allyn and Bacon.

Tooth, T. (2000). The use of multimedia in distance education. Vancouver, Canada: Commonwealth of Learning. Retrieved from http://www.col.org/SiteCollectionDocuments/KS2000\%20multimedia.pdf

Zhang, D., Zhou, L., Briggs, R. O., \& Nunamaker Jr, J. F. (2006). Instructional video in e-learning: Assessing the impact of interactive video on learning effectiveness. Information and Management, 43(1), 15-27. doi:10.1016/j. im.2005.01.004 